\title{
From Design to Practice: How can large-scale household surveys better represent the complexities of the social units under investigation?'
}

\author{
Antoinette Kriel ${ }^{a}$, Sara Randall ${ }^{b}$, Ernestina Coast $^{2 c}$ and B. de Clercq $^{3 d}$ \\ a Personal Finance Research Unit, University of South Africa (UNISA) \\ b University College London (UCL) \\ c The London School of Economics and Political Science (LSE) \\ ${ }^{d}$ Department of Taxation, University of South Africa (UNISA
}

\begin{abstract}
The way in which 'the household' is defined and operationalised in surveys and census data collection has long been criticised as unable to adequately capture the complexities of the social units within which people live. In a South African national survey on household wealth (HWS) a definition of the household was used to represent the ways in which South African households arrange themselves financially. Here we report on a quali tative study in which 36 households originally included in the HWS were re-interviewed to collect detailed data on household financial links and dependencies. Households with more complex structures, which represent the majority of household types in South Africa, were very poorly represented, and possible reasons for this are explored. We analyse and discuss the HWS research process in the light of the findings of this study, and propose ways to improve large-scale survey design and data collection, drawing on perspectives from multiple disciplines
\end{abstract}

Keywords: quantitative household survey concepts, organisational and structural complexity, representativeness

\section{Résumé}

La façon dont "le ménage " est défini et opérationnel dans les enquêtes et collecte de données de recensement a été critiquée depuis longtemps comme incapable de saisir adéquatement les complexités des unités sociales de la vie quotidienne. Dans un sondage national sud-africain sur la richesse des ménages (HWS) une définition du ménage a été utilisée pour représenter la façon dont les ménages sud-africains s'arrangent financièrement. Nous présen- tons ici une étude qualitative dans laquelle 36 ménages, initialement inclus dans le HWS, ont été réinterro- gés afin de recueillir des données détaillées sur les dépendances et les liens financiers domestiques. Les mé- nages avec des structures plus complexes, qui constituent la majorité des types de ménage en Afrique du Sud, ont été très mal représentés, et on en explore les raisons sous-jacentes. Nous analysons le processus de re-cherche du HWS à la lumière des résultats de cette étude et nous proposons des moyens d'améliorer la col-lecte de données et la conception d'enquête à grande échelle, s'appuyant sur les perspectives multidisciplinaires.

Mots clés: quantitative notions de l'enquête sur les ménages, la complexité organisationnelle et structurelle, représentativité

\footnotetext{
${ }^{1}$ The original research which underpinned this South African work was funded by ESRC (UK) under the Survey Design and Measurement Initiative (RES-175-25-0012: PI Ernestina Coast) and under the collaborative ESRC-ANR research programme (RES 062-33-0007: PI Sara Randall).

${ }^{2}$ Dr Coast's work in South Africa was supported by a grant from STICERD, LSE

${ }^{3}$ Corresponding Author: Bernadene de Clercq; E-Mail: dclerb@unisa.ac.za; Cell:+27 83442 4659; Fax:+27 124296225
} 


\section{Introduction}

The household is used both as unit of analysis and as enumeration unit for survey and census data collection. Relationships within households are mostly indicated with regard to 'household head' or 'acting household head' with implications for analyses involving household forms and structures (Budlender 2003). The way in which the household is defined in surveys has been criticised by anthropologists and sociologists as unable to capture adequately the complexities of the social units within which people live (Hosegood and Timaeus 2006). In this paper we use one nationally representative survey - the South Africa Household Wealth Survey (HWS) - to examine the ways in which the household is defined and operationalised and how this may impact on the quality and representativeness of household data collected by the HWS.

\section{Literature review and theoretical frame- work}

Collecting data at a household level is a cost and time effective way of collecting social science data, especially in resource-poor settings with inadequate administrative information. Household survey data are essential to produce evidence to inform policy and development strategies, underscored by the Marrakech Action Plan for Statistics (World Bank 2004) to improve all aspects of household survey data production, from planning to design to execution and analysis (Randall, Coast and Leone 20 I I).

However, the use of the household in data collection has been highlighted in the literature as being problematic, and in need of being recognised as such, for over three decades (Guyer 198I) especially when attempts are made to pre-define, standardise and harmonise the concept for survey data collection purposes because households are multidimensional, complex and fluid (Hosegood and Timaeus 2006). The way in which the 'household' is defined in household surveys (referred to as the 'statistical household') often bears little resemblance to the social unit in which people live (Rao 1992, Cloke 2007). Many disciplines emphasise the importance of comparability of concepts over space and time and encourage the adoption of clear, unambiguous and unchanging definitions, leading to harmonisation of instruments and data (Randall et al 20II). Since the UN Statistical Commission began its capacity-building programmes, greater emphasis has been placed on countries to comply with international standards when receiving assistance with data collection. This has led to greater homogeneity in the definitions of concepts such as the household.

Many established household definitions (e.g. from the United Nations Statistics Division Department of Economic and Social Affairs (UN DESA 2008) and the System of National Accounts (SNA) (2008)) define the household according to aspects of place and/or pooling of resources, also described as 'sleeping under the same roof' (co-residency) and 'eating from the same pot', the latter being a proxy for an economic unit. Definitions focusing on coresidency tend to give rise to the de facto household.

\section{South Africa}

Due to South Africa's political and economic history, the country has highly mobile urban and rural populations as well as complex, fluid household structures, often associated with migrant labour (Hosegood and Timaeus 2006). In an attempt to account for this flexibility of living arrangements within the South African context, Statistics South Africa defines the household as:

... a person, or group of persons, who occupy a common dwelling unit (or part of it) for at least four nights in a week on average during the past four weeks prior to the survey interview. Basically, they live together and share resources as a unit. Other explanatory phrases can be 'eating from the same pot' and 'cook and eat together'

(Statistics South Africa 2010:19).

The emphasis is placed on the sharing of resources with some flexibility as far as living arrangements are concerned, the so-called ' $4 \times 4$ rule'. As is the case with other 'statistical household' definitions, the Statistics South Africa definition is specifically formulated to avoid double counting of individuals. Although this is important for total enumeration data collection exercises such as a census, there are important limitations of this requirement when attempting to understand and make statements about household dynamics, particularly when focusing on economic units (units of production and consumption). In research that took a much more flexible approach to the household definition in studying rural households in KwaZulu-Natal, South Africa (Hosegood and Timaeus 2006), it was found that:

I. non-residents are also considered members of rural households;

2. individuals may belong to more than one household; 
3. some individuals live with households they do not belong to fully but at the same time do not function as separate households either.

Definitions in which the avoidance of double counting is a priority, and which are based primarily on co-residence, are often inadequate at capturing the social reality. Attempts to standardise and predefine a concept that is multi-dimensional, complex and fluid, and essentially subjective and 'fuzzy' (Hosegood and Timaeus 2006) have implications for the way in which household composition, production and poverty statistics are understood (Beaman and Dillon 2010). This is because the movement of people between households is an important means by which households cope in resource-poor situations both in South Africa (lones 1993, Spiegel 1996) and elsewhere in Africa (Guyer 198I, Little et al 2005, Mushongah and Scoones 2012, Whitehead 2006). The enumeration only of resident members, or those resident for four days or more per week, limits the exploration of intra-household relationships, transfers and economic interdependencies. It can also mean that an incomplete profile of the composition of the household is recorded: for example, where a male migrant is considered by the household to be the head and fieldworkers collecting the data arbitrarily assign headship to a resident member, such as the spouse (Hosegood and Timaeus 2006). Other authors (Townsend 1997, Guyer and Peters 1987, Murray 1981, O'Laughlin 1998) have similarly concluded that the residential household is an inadequate unit of analysis with which to explore many social and economic processes in Africa. Instead of considering co-residence or 'eating from the same pot' as important criteria for household membership inclusion, aspects of kinship, shared responsibilities and authority, and historical relationships are defined by respondents as important criteria for inclusion (Hosegood, Benzler and Solarsh 2005). The uncritical use of household definitions in surveys can therefore potentially be problematic when using survey data in policy-making and in the design of development programmes.

Much of the critique of household survey definitions stems from research conducted in selected southern African contexts. However, an oversimplified view of black South Africans exhibiting complex household structures compared to white South Africans necessarily being simple conjugal structures needs to be avoided:

When we thus want to research different households in South Africa, we should acknowledge the diver- sity found amongst black African households, white households as well as all other racial groupings found in South Africa (Rabe 2008: 173).

Rabe questions the adequacy with which the heterogeneous dynamics of South African households are captured by both the General Household Survey and the Census, which focus on de facto household members and not de jure members (Rabe 2008).

In-depth interviews conducted with men working at a mine south-west of Johannesburg show how complexities of household dynamics are unaccounted for when surveys concentrate only on de facto household membership (Rabe 2006). Comparing the Africa Centre Demographic Information System (ACDIS) data collected on households using a method of self-reporting of the household boundaries to the de facto census population data (ACDIS 2007) highlights the extent to which the census overestimates the rate of female headship and underestimates the size of households, with implications for household-level analyses (Hosegood and Timaeus 2006).

\section{Research problem and aims of paper}

With reference to the HWS, this paper:

I. explores how concepts such as the household were understood and operationalised by different actors in the research process;

2. describes to what extent the HWS captured different configurations and situations within South African households; and

3. examines how different household unit definitions may impact on the data collected.

Definitions are by their very nature limited and will never be able to capture every situation. The study did not endeavour to find 'better' definitions or a single definition, but rather highlights the limitations of a household definition for the interpretation of findings.

This study uses the HWS as a case study to understand how households are captured and represented by a nationally representative South African survey. The purpose of the HWS was to collect household-level data on income, expenditure, assets and liabilities. Although South Africa has household surveys such as the General Household Survey (Statistics South Africa 2010) and the All Media and Products Survey (AMPS) (SAARF 2012) that collect data on some household assets and liabilities, net wealth measurement per se is not the primary focus of these surveys. As a result, these surveys lack information on the components of the household balance sheet and therefore one of the objectives of 
the HWS was to address the lack of disaggregated data on South African household assets and liabilities. The HWS was designed by researcher experts in financial issues, and who consulted widely with other research groups investigating similar issues. In developing the survey instrument, the first draft thereof was finalised by incorporating feedback from experts, elicited via focus group discussions. A faceto-face focus group involved participants selected for their knowledge of South African household finance and/or household financial surveying, and included local representatives from South African financial services (i.e. retail banks), the South African Reserve Bank (SARB), the National Treasury, the Association for Savings and Investment South Africa (ASISA), academia from the University of South Africa (Unisa) (SA), the Personal Finance Research Unit (PFRU) at Unisa (SA), the North-West University (NWU) (SA), the University of Cape Town (UCT) (SA), Stellenbosch University (SU) (SA), and the University of the Free State (UFS) (SA). An online focus group was held with international experts from the Bank of Italy, London School of Economics (UK), Oxford University (UK), Nuffield University (UK) and Bristol University (UK).

During the focus group discussions, issues regarding the definitions of a household and the person with whom the interview should be conducted were discussed. An expert on financial surveys from the European Central Bank assisted the HWS team to obtain permission from the European Central Bank/Household Finance and Consumption Network to use the Network's core output variables (Eurosystem HFCN 2009) for the HWS. Two concepts are key here: A Financially Knowledgeable Person (FKP) and the Wealth Creation Unit (WCU).

The FKP was defined as:

The person who is most knowledgeable on financial matters about both the household as a whole and its individual members (Eurosystem HFCN 2009).

The HWS survey designers conceptualised the unit of data collection and analysis as a financial unit known as the 'wealth creation unit' (WCU). The WCU was viewed as comprising individuals with familial links who pool their funds for the purpose of long-term financial well-being, although these individuals do not have to live under the same roof. For example, the WCU aimed at including a person working away from home for four days a week and only returning over weekends - in terms of the ' $4 \mathrm{x}$ 4 rule' this would result in two households but with only one WCU. This generates a potentially incomplete overlap between the residential unit and the financial unit to which an individual might be assigned. The HWS survey designers felt that the Statistics South Africa ' $4 \times 4$ rule' definition of the household would not adequately capture the financial data that the HWS sought to collect as the time limits it imposes made it insufficiently flexible. A WCU definition was therefore chosen that would, theoretically, permit the survey designers to take into account the diversity of living arrangements within the South African context as well as population mobility (where some household members might work and live in different areas) with no timeframes imposed. It was decided to adopt the definition as defined by the core output variables (Eurosystem HFCN 2009) for the HWS:

Household is defined as an economic unit consisting of a person living alone or a group of people who live together in the same private dwelling and share expenditures including the joint provision of the essentials of living. Employees or other residents (i.e. live-in domestic servants, au-pairs, etc.) and roommates without other family or partnership attachments to household members (e.g. resident boarders, lodgers, tenants, visitors, etc.) are considered as separate households.

Subject to the further and specific conditions shown below, the following persons must, if they share household expenses, be regarded as household members:

I) persons usually resident, but temporarily absent from dwelling (for reasons of holiday, travel, work, education or similar)

2) children of the household being educated away from home

3) persons absent for long periods, but having household ties: persons working away from home

4) persons temporarily absent but having household ties: persons in hospital, nursing home, boarding school or other institution (Eurosystem HFCN 2009).

This definition was viewed to be covering most of the living arrangements of South Africans. The principle where the household is seen as an economic unit that pools resources and shares mutually in wealth was also maintained.

\section{Data and methods}

The HWS, conducted in 201I, involved interviews with individuals from a representative" sample of 2606 South African households, of which approximately $60 \%$ were face-to-face interviews and approximately $40 \%$ were telephone interviews. The findings presented here relate to a qualitative follow- 
up study, which was conducted in 2012 (Step 3 in Figure I). Three research methods were used: indepth interviews with original HWS sample members $(n=48)$, group interviews with HWS interviewers $(n=4)$, and a review of HWS documents. As a qualitative study, this research was dependent on those who were willing to be re-interviewed. It would therefore not be appropriate to give percentages or quantitative indicators of the qualitative results, as we did not seek to quantify the scale of any effects. Figure I provides an overview of the research process and methods.

\section{Step 1}

Household Wealth Survey design phase January - July 2011

Financial expert consultation - discussions with number of external organisations about what to include in questionnaire (general topics only discussed, not questionnaire design issues).
Literature review and in-group discussions on how to define a household, including discussions on concept of "wealth creation unit".
Financial and household budget survey design experts review questionnaire.

\section{Household Wealth Survey}

August - October 2011

Financial information (income expenditure, assets and liabilities) was collected from "households" and individuals within households

- A questionnaire was completed either by means of face-to-face interviews in people's homes (approx. $60 \%$ ) or telephonically (approx. 40\%)

- Questionnaires were in English only but interviews were conducted in whatever language "agreed" upon between interviewer and interviewee

- Wards and regions (urban and rural) within all 9 South African provinces were randomly sampled. Interviewers from the selected areas were trained and assigned a specific ward within which to work. They were instructed to interview one household per street, selected randomly by the field worker.

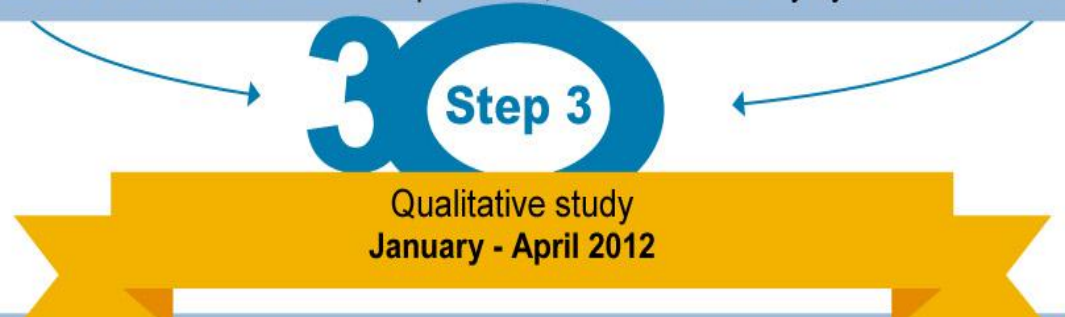

Aiming to examine understandings of key concepts in survey and to find out extent to which is succeeded in capturing and representing different household situations

Group interviews $(n=4)$ with HWS field workers in 4 provinces.
Gaining insights into how field workers understood and operationalised concepts such as household and financially knowledgeable person.

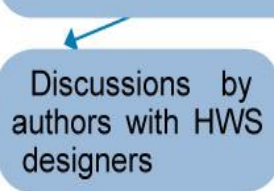

\section{$\rightarrow$}

Qualitative in-depth interviews with original HWS respondents $(n=48)$ in 4 provinces.
Collected in-depth information on inter- and intra- household familial and financial links.

Figure I: Steps and methods 


\section{In-depth interviews with original HWS sample members}

Thirty-six households from four provinces that took part in the HWS were re-interviewed face-to-face and 12 households were re-interviewed telephonically to collect detailed qualitative information about inter- and intra-household financial links and dependencies. The same individual who participated in the original survey was re-interviewed wherever possible and any other available members were included in order to obtain multiple perspectives. This approach also allowed for discussion about interpretation of concepts by respondents.

Respondents who were originally interviewed on a face-to-face basis were re-interviewed in their homes wherever possible (some were interviewed at their places of work) and in their preferred language. Those who were originally interviewed telephonically were again contacted by phone. All English-speaking interviewers were accompanied by a translator/interviewer who could speak the respondent's language fluently. The majority (40) of re-interviewed households were black (different language-speakers) and 8 Coloured, Indian and white (mainly Afrikaans-speaking) households were re-interviewed telephonically.

The semi-structured interview information on household members, reflecting kinship, living arrangements and employment was recorded in a grid format so that all members' details were visible to the interviewers at all times. Details of whether or not unit members had eaten and slept at the residence the previous night and whether they had slept there on average four nights a week for the preceding four weeks were also recorded so that units could be classified according to the Statistics South Africa household definition. Probing questions were asked in an attempt to arrive at as complete a picture as possible of the people resident in the house, their diverse familial and financial links, as well as anyone not resident in the house with familial and/or financial links (thus specifically pursuing points I, 2, 3 and 4 in the household definition used for the purposes of the HWS). Relationships were not recorded with the household head but with the relevant person(s) in the unit. This allowed the identification of smaller nuclear parent-child units within larger units (often somewhat but not totally financially autonomous) and also allowed more detailed recording of relationships where individuals were members of a household not because of their relationship with the household head but with another member of the household (e.g. the niece of the household head's wife). Exploring these different relationships also allowed the identification of absent people who may be considered members for some purposes. Units were analysed according to different household and financial unit definition requirements and differences/similarities compared. Respondents were also asked about the extent of their knowledge of others' financial situations and their ability to report this information. Notes were made so that a profile of the household could be constructed. This was used to compare with the HWS household profile that could be reconstructed from examining the original HWS questionnaires.

\section{Group interviews with HWS interviewers}

Group interviews were conducted with fieldworkers from four provinces who were involved in the original HWS. They sought to ascertain the way in which fieldworkers had understood concepts such as 'household' and the FKP, and the way in which they had operationalised these concepts during the data collection process. The qualitative study also included in-depth discussions with some of the original survey designers regarding their understanding of the term 'household' and how they understood the interplay between social and financial units.

\section{Results}

Household membership information (headship, composition, structure) and FKP information from each qualitative interview was compared with data collected in the original HWS.

Our analyses revealed three main themes:

Theme I: Problems associated with the HWS survey concepts;

Theme 2: Fieldworker training, understanding and application of the HWS; and,

Theme 3: Importance of inter-household financial links.

\section{Theme I: Problems associated with the survey concepts}

Discussions with HWS researchers revealed that the HWS involved three key concepts that are relevant to understanding how the survey was conceptualised by the designers: the wealth creation unit (WCU), the household, and the FKP.

The HWS household definition was chosen on the basis that it would best capture the researchers' concept of the 'wealth creation unit'. This household definition differed from the Statistics South Africa ' $4 \times 4$ rule' definition in that it included mem- 
bers living and working away from the main residence for extended periods of time. However, an analysis of survey definitions highlights internal inconsistency: it first defines the unit as those who 'live together' but then includes a list of people iii who do not live together. It nevertheless allows for greater flexibility in recorded interrelationships: people from Group 3 ('persons absent for long periods, but having household ties: persons working away from home') would not be considered household members by most other household survey definitions. The difficulty arises in operationalising this group. Without clear guidance on what constitutes 'having household ties' or even what constitutes 'sharing household expenses', it is not at all clear how these people may be identified. Such definitional ambiguities make operationalising the concept in the field very difficult for the interviewer. It is also questionable whether or not the household as conceptualised and operationalised by the survey designers is a clearly identifiable entity for many people. Data from the in-depth interviews revealed that there was rarely complete overlap between the WCU as conceptualised by the survey designers and the way in which it was operationalised. Application of the Statistics South Africa definition of the household, as often, gave very different household unit formations. Case study I below not only highlights this incomplete overlap but also indicates issues posed by the HWS designers' concept of the wealth creation unit.

Case study I: A mother (housewife), father (employed) and their 13-year old son - a 'middle class' family living in Soweto, Gauteng. The son lived with the grandmother during the week during term time so that he could attend a better school. His parents paid for his upkeep at his grandmother's. Although this is a very 'simple' nuclear family mother, father, child - it would not constitute a household under the Statistics South Africa's ' $4 \times 4$ rule', as the child stays elsewhere for more than four nights of the week during term time, making this a two-person household. The HWS household definition would, however, include the child, making this a three-person household - which, from the point of view of both expenditure and mutual support, is a good representation. However, when we compare the qualitative follow-up study with what was recorded in the original HWS, we find that there was no indication of the child's living and financial arrangements. Given that the grandmother is making a major contribution to the son's human capital (by providing appropriate accommodation) it could be argued that she, too, should be considered as part of the wealth creation unit. This example highlights the imperfect overlap between the concepts of the WCU and the household in the HWS.

By comparing retrospective in-depth interview responses with the original data collected in the HWS, we were able to identify specific issues in the coverage and quality of household data. Problems associated with the application of the household concept led to specific situations being misrepresented in the HWS:

I. Omissions of household members in the HWS tended to be occasional co-residents who were financially dependent on, or contributed to, the household. These cases were most commonly found in complex households, including: nuclear households with migrant-worker members (e.g. parents or children working or studying away from home) (Case Study 2); and, households with very 'fuzzy' boundaries containing complex links and flows between two or more households (Case Study 3).

2. In a number of cases regular co-resident members were omitted from the original HWS, attributable to issues related to the interviewer (see next section). Again, analyses of the indepth qualitative interviews indicates that many of these households were more complex (e.g. large households; multiple-generation households, complex relationship links (or sometimes none at all) between household members). The task of making sense of such structurally complex units was made even more difficult in the HWS because (as is the case in many household surveys) of the linking of everyone's relationship status to just one person, the 'household head'.

Case study 2: According to the original HWS data, this was a two-person household of a young man in his twenties and a five-month-old baby, with no other household members. In almost every sociocultural context, this would be an unusual domestic set-up. However, when we re-interviewed the man, a forklift driver, it transpired that he had been off work, ill, on the day the HWS survey interviewer arrived. At the time of the HWS his girlfriend and their baby lived with her parents, due to a lack of space, but on the day of the survey interview, he had been looking after the baby while his girlfriend went to do some shopping. At the time of the original survey he had a room in a shared family house shared with half-brothers of his father's other wife he shared bills in general but no other arrangements. This raises the question of whether, according to the 
HWS definition, he and his half-brothers should have been a household; whether he alone should have constituted a household; or whether his girlfriend and baby should have been included because, according to the respondent, they shared all money and budgets and would therefore be able to answer all questions pertaining to each other's finances. At the time of the HWS his girlfriend and baby would come to stay every weekend, meaning that they would not qualify under the Statistics South Africa $4 \times 4$ definition of a household, as they would only be there eight days per four weeks. If the Statistics South Africa definition had been applied, the de facto residential unit would have been captured, excluding the girlfriend and child (Figure 2).

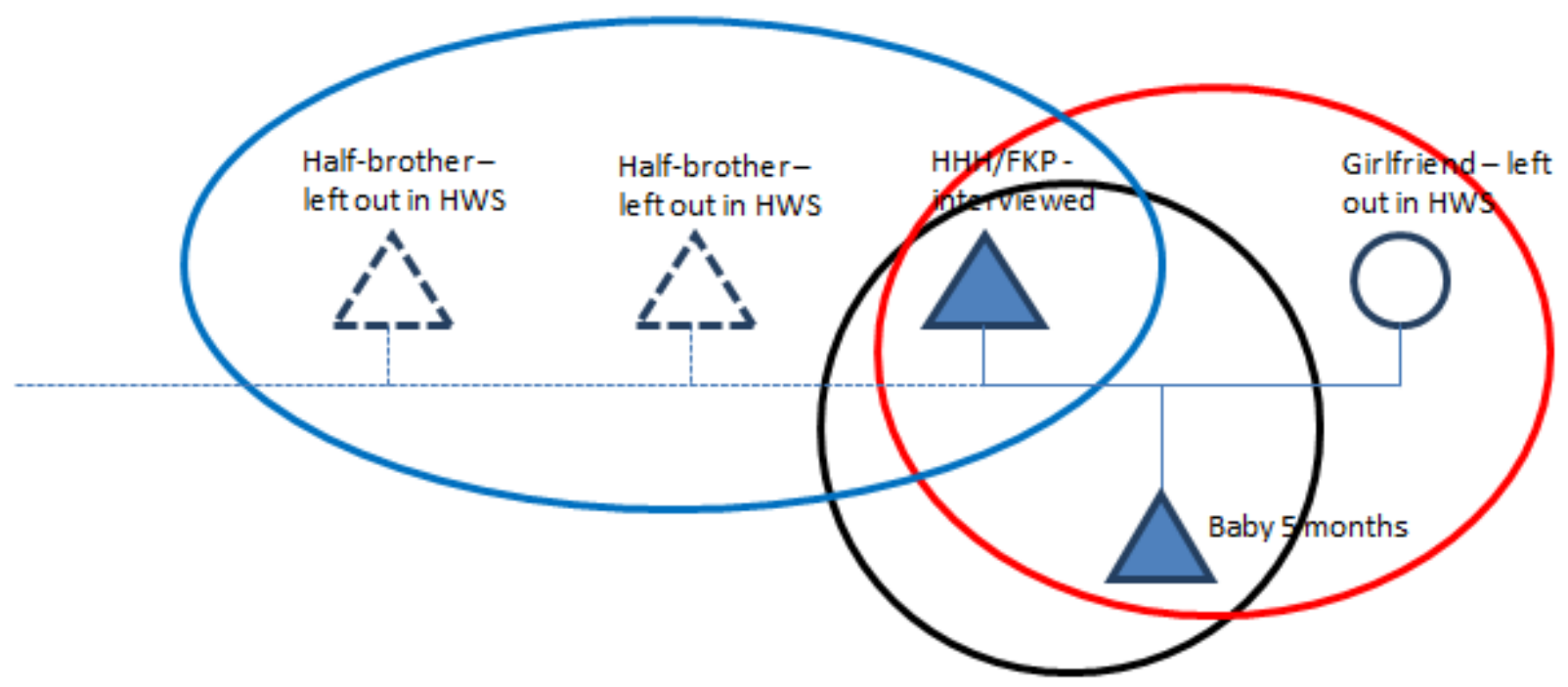

Figure 2: Example of different conceptions of the household

[key]: Statictics South Africa household

Household recorded in qualitative interview using HWS household definition Household as recorded by HWS interviewer

Case Study 2 is an example of an HWS interviewer recording who was there at the time of the interview (de facto), ignoring Points I to 4 of the HWS household definition. The reason for this omission could reflect miscommunication of concepts by the survey designers and/or lack of proper training in interviewing techniques (i.e. use of probing questions).

Many of the households that were reinterviewed were complex, included multiple generations and being fluid, they were not sought out by the qualitative study, they were those who had agreed to potential follow-up and that the authors were able to contact. In these situations there were more cases of 'fuzzy' membership in terms of both the WCU as conceptualised by the HWS designers, and the survey household (Case study 3 ).

Case study 3: Minah and Queen are sisters in their early thirties living with their children and their younger sister in a village in Limpopo (Figure 3). They make a living by doing infrequent piece jobs combined with contributions to electricity and groceries from Queen's oldest son's job as a petrol attendant. The house is owned by Minah and Queen's father who works in Johannesburg where he also owns a Reconstruction and Development Programme (RDP) house ${ }^{\mathrm{i}}$. Although the father does not live in Limpopo, in the follow-up qualitative interview he was recorded as the head of the household, in part because he provides for Minah and Queen financially, without which they felt they would not be able to survive. Although he only visits the Limpopo residence during holidays, their father's financial input is an essential part of the well-being of the household. It could be suggested that the household consists of the members as indicated in Figure 3 (excluding Minah's ex-partner). However, it is unclear whether or not the household should include the father and brother due to inherent ambiguities in the HWS definition. In the qualitative indepth interview, Minah reported that the finances of her father and Queen's son were not known about by the respondent to the original HWS, with implications for the quality of the financial data collected from this household by the HWS. 


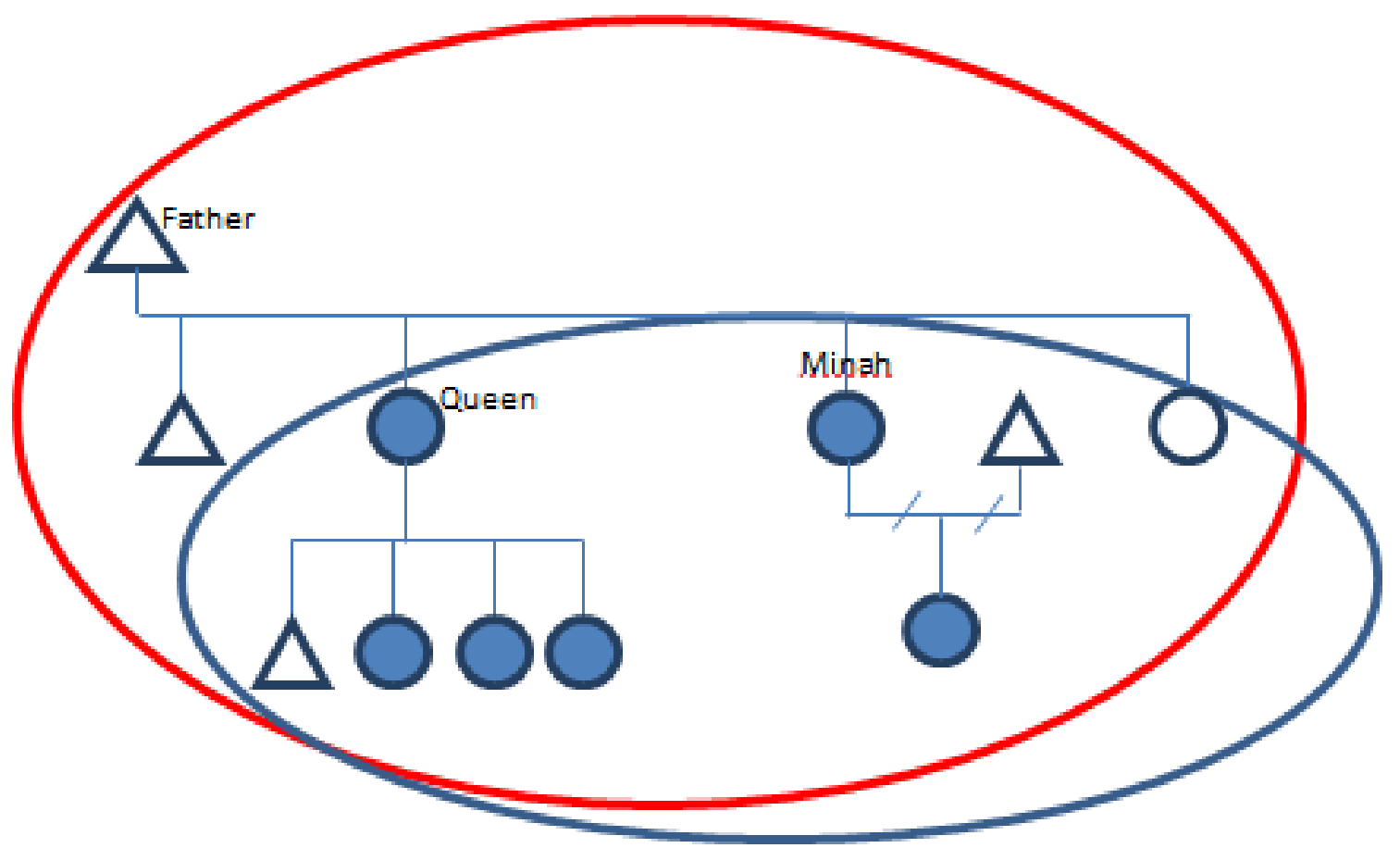

Figure 3: Example of a structurally and organisationally complex household

[key]: Household recorded in qualitative interview using HWS household definition

Statistics South Africa household
Recorded by HWS interviewer
Omitted by HWS interviewer but included in qualitative follow-up interview

The original HWS did not include the Johannesburg-based father and brother of Minah and Queen (although the RDP house was recorded as a second residence), nor did it include their younger sister or Queen's son. When our in-depth interview probed why this might have happened, it was reported that they were temporarily away at the time of the HWS. The interviewer therefore based household membership on de facto residence and did not probe to detect these temporarily absent members. Multiple flows of financial support into this residential unit were also not recorded. For example, financial contributions from Minah's ex-partner to the support of their daughter were not reported. Such omissions impact significantly on the accuracy of the financial data collected. No household head was recorded on the questionnaire and Minah was indicated as the FKP. Since relationships were recorded with reference to the household head, this made the relationships, and thus analysis of the household structure, incomprehensible in the HWS data.

\section{Theme 2: Fieldworker training, understanding and application of the HWS}

In the original survey training, fieldworkers were trained in the survey-specific concepts of the household as well as the FKP, but not the WCU. Fieldworker interviews highlighted a lack of clarity about the notion of the household and how it differs from a WCU - especially those interviewers with poorer English. This included confusion as to whether 'household' referred to a group of people or an individual. Household was not a word or concept in everyday use by the interviewers. Depending on the language in which the survey was conducted, the word 'household' would be translated into words meaning either 'family' or 'home'. This is a fundamental issue in multi-lingual South Africa where different languages have different concepts that best approximate to a survey household. The operationalisation of the requirement to include kin involved in household support but living elsewhere was very inconsistent. 
Interviewer: So now what's your understanding of a household?

Fieldworker: Ja, a household it's a family. A family of people who are living together. Everyone in the family. Ja, when I get to the house then I find those people there. And then I interview those people. Those people to me they were all household to me in those family. I understand it like that. Beside the financial responsible person (Mpumalanga fieldworker interview).

Some fieldworkers integrated the financial aspects of the survey with their initial [mis] understandings of the concept of the household to create new meanings:

Fieldworker: For me, I used to know this word, but when it came to the survey I realised that households explains a lot of things in it. So before I was just calling it 'the home'. So for me it was just 'homes.' And then when I did the survey I realised that 'home' is not only called homes because now there are a lot of things involved for it. You can talk about all the things that are involved there, it is called 'household' because you've got families inside, you've got how they spend their money, what they have, you've got properties and the assets. So I just came to the conclusion that the households just sum up all those things that they do in that home (Gauteng fieldworker interview).

Fieldworkers introduced their own criteria. Here 'money is involved on a daily basis':

Fieldworker: l've explained to the interviewees that a household is a place where people live and whereby money is involved on a daily basis and since most of the people that I was interviewing are not familiar with English so I had to explain everything to them - what does this mean, what does this mean and eventually we could understand one another. But at first it was very difficult because people were reluctant (Mpumalanga fieldworker interview).

The next fieldworker highlighted that he developed a further requirement to define the household, the presence of a main breadwinner:

Fieldworker: The way I explained them the household, the family where they share resources. They share resources and there must be one person who is the main breadwinner (Mpumalanga fieldworker interview).

What these interview transcripts show is that although the survey designers and analysts had a clear idea of a household (which they equated with the WCU), this was not conveyed adequately to the fieldworkers for whom the basic unit of data collection was something approximating the survey household - but which could be either residential or economic or kinship-related or some mix of the three, depending on their individual understanding. Fieldworkers all saw 'household' as an external analytical concept developed for the survey, which they had to somehow apply during their interviews.

Fieldworkers were told to identify the FKP, defined as the person who is the most knowledgeable about financial affairs of both the household as a whole as well as its individual members. The FKP was then asked to provide much of the detailed financial information required by the HWS. However, according to the interviewers who took part in the group interviews, in many cases they interviewed whoever was available. In most instances only one person was interviewed and therefore was assigned the role of the FKP within the household, which would have entailed giving details of individuals' incomes, assets and liabilities as well as general expenses of the household as a whole. Of the 36 households re-interviewed (face-to-face) only two indicated that more than one person was interviewed during the original HWS. Most of the respondents indicated that they had financially-related knowledge concerning only part of their household. For others, if they did know about other household members' finances they did not feel at liberty to divulge that information without the consent of the individuals: one respondent felt she could not answer financial questions for grown-up children; an adult daughter interviewed as the FKP, living with her mother, did not feel she had the right to give information about her mother's finances - who was at work at the time of the original interview - even if she had the information.

The group interviews with interviewers and follow-up interviews with households revealed inconsistency and confusion about whether the respondent (who may or may not have been the FKP) was then systematically recorded as the household head. Some respondents were both the FKP as well as the household head, but in other instances the household head and the respondent (FKP) were not the same person although the FKP was wrongly ascribed the role of household head. Such lack of clarity is likely to generate problems in terms of understanding household structure as relationships were only recorded with the household head. It also became clear from the follow-up research that interviewers often simply interviewed whoever was at home and available. So for instance in Case Study I (above), the HWS survey interviewer interviewed the wife, although the husband was recorded as both the 
household head and the 'FKP'. During our followup interview she reported that she had had difficulty answering questions on her husband's income and finances, reflected by several missing variables in the HWS dataset for this particular household.

\section{Theme 3: Importance of inter-household finan- cial links}

Most of the households that were re-interviewed indepth indicated informal financial links with other units and individuals, which would have been important in understanding the households' financial well-being. The financial support to and from other households could be in the form of money or goods, such as groceries. In some instances the support came in the form of improvements to property or providing transport. Absentee fathers of children often give regular or occasional support to the children or pay the children's school fees, yet are not considered part of the household from the perspective of the respondents re-interviewed during the qualitative study.

\section{Discussion}

The findings of the follow-up study indicate major difficulties in I) taking the unit of analysis from design to practice; 2) dealing with the particular complexities of South African 'households' where key complicating factors include: extensive labour migration of both men and women; numerous children from informal unions and non-co-resident fathers (associated with considerable spatial and temporal mobility of children); and, economic and employment types characterised by financial interdependencies across residential units.

Discussions with survey designers highlighted the fact that they had a conception of the unit of data collection as the 'wealth creation unit (WCU)' which they tried to operationalise through the 'survey household', both of which differed from the Statistics South Africa household definition. The Statistics South Africa definition would have been inappropriate for a financial study of this type, since it is basically a residential definition designed primarily to avoid double counting. The assumption made by the survey designers was that the concepts of the WCU and the household were one and the same (when they were actually different) and hence survey training and documentation only included the HWS household definition. The way in which the unit of data collection was understood therefore differed between the survey designers and the fieldworkers. A lack of clarity with regard to the unit of data collection and ambiguities in the survey household definition resulted in different actors within the research process working with different understandings of the unit under investigation resulting in the definition being applied inconsistently by the fieldworkers. Although the training included discussions around the different definitions of survey concepts, including that of 'the household', it was dealing with concepts that were foreign to many of the fieldworkers that proved problematic. Priority was given to recruiting fieldworkers who were from the communities where they would collect HWS data as it was assumed that this would facilitate recruitment of respondents and improve data quality. This recruitment strategy restricted the selection of fieldworkers, especially in more rural areas, which meant that availability became the overriding criterion, over and above English language skills and level of education. Fieldworkers with poor English skills had little understanding of the household concept at all. Those with a good command of English seemed to associate it with more familiar concepts, such as 'home' and 'family'. Different meanings and interpretations of the household concept were therefore applied by fieldworkers. Non-resident household members were either included or excluded depending on the fieldworkers' personal experiences and understandings. Even within one survey and one team, multiple meanings of individual concepts coexisted. This situation was exacerbated in a multilingual setting (common throughout sub-Saharan Africa) where similar, but not identical, ideas are contained within the language-specific terms used to translate key concepts. We need to better understand how concepts such as the household, home and family are understood, interrelated and represented across languages.

A major problem of household survey research processes is that the unit of data collection and analysis may be regarded as secondary to the primary focus of the survey, in the case of the HWS, the financial domain. We identify two key components of the survey process that are affected by a lack of proper consideration given to the operationalisation of analytic concepts (such as the WCU) in the field. Firstly, that fieldworker training needs to be much clearer about the units of collection and provide fieldworkers with appropriate skills and probing questions to be asked to identify 'missing' individuals, i.e. individuals who should have been included but were not mentioned. Secondly, the research instrument needs to be flexible enough to record different familial and or financial links between indi- 
viduals so that a more complete understanding of the unit of data collection and analysis is possible.

Results from this study indicate that a lack of interviewer experience and training in effective probing techniques meant that interviewers often did not understand the complete household situation prior to completing the questionnaire, often leading to erroneous omissions or inclusions of individuals. The structure of the questionnaire and the way in which relationship information was collected also did not facilitate such an understanding of the household situation, as information about adults and children was collected and recorded separately, and complex relationship situations were reduced to pre-coded relationships with the household head only.

Sociologists have long criticised the use of the household head as the axis around which the household is arranged and defined. Our analyses support this position and demonstrate that collecting data only on the basis of relationship to household head is not flexible enough to work for units that are organisationally and structurally complex. The results of the follow-up qualitative study indicate that the household units best represented by the original survey were not necessarily typical 'nuclear' structures - very few of the households re-interviewed displayed nuclear family characteristics - but had the following characteristics in common:

- Structural simplicity (ie: in terms of generational structure);

- Self-contained (few or no links with other households)

Organisational simplicity, i.e. living arrangements of household members was uncomplicated.

Households that were poorly represented by the original HWS had the following characteristics in common:

- Organisational and structural complexity (e.g. many relatives living together with complex financial and organisational links with other households)

- Irregular living arrangements, often including a lot of movement between household units

- Larger households (more than ten members)

The household types best represented by the original survey were either organisationally and/or structurally simple and were generally relatively selfcontained units, financially and socially. Such households did not exhibit a great deal of fluidity in terms of movement of individuals into and out of the residential unit. There were few financial flows into or out of these households, either from or to other households or individuals. Those that were poorly represented by the original survey, e.g. missing individuals or individuals erroneously included, tended to be organisationally and structurally more complex. They were, for example, nuclear-type households but with many family members working away as migrant workers. Some were structurally complex with many distant relatives or even nonrelatives living together and sharing resources. Other households were both organisationally and structurally complex (Case Study 3).

The more closely the residential unit overlapped with the economic unit, the better the fieldworkers were able to capture the unit in the HWS. Fieldworkers struggled to accurately capture units where there was little overlap between the residential and economic units. In these instances good probing skills, a better, more consistent and less ambiguous understanding of the unit of data collection, as well as a questionnaire that encouraged a more complete understanding of the social domain would have prevented many of the inaccuracies present in the data collected. The case study of the HWS shows that, over and above better survey planning (and training), there is a need for compromise between an analytic concept (here, the WCU) which does not necessarily neatly map onto a concept (the household) that can be operationalised in the field by interviewers.

The research designers used a particular definition of the household as an economic unit to operationalise the concept of the wealth creation unit. However, the way in which the two concepts relate to each other was problematic. Firstly, there was an incomplete overlap between the two concepts in many of the households that were re-interviewed. Some survey households included what could be regarded as more than one wealth creation unit, whereas other survey households excluded individuals who, it could be argued, should have been included as part of the WCU. The follow-up interviews indicate that the organisational and structural complexities of many households make it difficult to draw definitive boundaries around either residential households or financial units - let alone assume that one equals the other. Without first understanding this complexity one risks misrepresenting the financial situations of more complex household units.

From the follow-up qualitative study it was clear that although the meaning of the term 'financially knowledgeable person' may have been explained to the interviewers during training, the potentially different roles of the FKP, the respondent and the 
household head were not clarified adequately. This is clear from the different ways in which interviewers conceptualised these relationships with some equating the FKP with the household head, and others realising that the FKP and the household head could be different individuals. A few interviewers also realised that there could be more than one FKP in a household. However, logistics did not always allow them to act on this realisation as it was very difficult for them to go back to households at a later stage due to time and financial constraints. This is a limitation that should be given serious consideration by similar surveys as it could potentially hamper the completeness and accuracy of information collected. Other studies have also demonstrated imperfect and inadequate financial information provided by others as shown by Fisher, Reimer and Carr (2010) in Malawi, where there were substantial inaccuracies in information given by husband and wife couples when asked about the other person's finances.

The follow-up interviews with the households indicated a considerable amount of inter-household financial flows. Because of the ambiguities inherent in the HWS household definition it was not always clear whether these units should qualify as a single wealth creation unit or not. It highlighted the importance of giving due consideration to understanding the social domain of the unit of data collection although the primary focus of the survey is the financial domain. An inadequate understanding of the social unit that forms the basis of data collection will potentially undermine an understanding of the other domains due to the unresolved complexities inherent in the social unit. At present there is inadequate understanding of how the social and financial domains of South African households intersect and shape each other. The households interviewed in this study were in urban and semi-rural (villages) locations, showing that issues of complexity are not confined to deep rural areas of South Africa.

\section{Conclusion}

Large-scale quantitative household surveys can be criticised (but often are not) for their inability to adequately represent the complexities of the household units under investigation. The inadequate use of the statistical household definition to represent complex and 'fuzzy' social units is often not recognised. An analysis of the assumptions made about living arrangements by designers of a specialist financial survey and how concepts such as 'household' were understood suggests a lack of understanding by survey designers of the relationship between the social and other (e.g. financial) dimensions of the household unit. In this regard financial experts with a wide range of experience world-wide and in Africa were consulted but they either did not, or were not asked to comment on the basic data collection units.

Obtaining input from a wide variety of social researchers - and not only those interested in the actual subject matter of the study - is one way of addressing this issue. Multi-disciplinary inputs to all specialist surveys would be an important step towards getting large-scale specialist household surveys to better represent the complexities of the social units under investigation and thus also improve the overall quality of data collected.

In designing the survey there were multiple consultations with a number of stakeholders over the financially-related concepts - including the WCU. From a financial perspective it was clearly a well thought through study - but it failed to take account of the complexity of actual living arrangements on the ground and how 'wealth creation units' may intersect with different household arrangements. Without paying serious attention to the basic social units for which data were recorded and the ways in which individuals were included/excluded (including how these individuals were identified in the first place), the wealth creation units may only be partially identified.

Having recognised the complexities of the South African household context, the HWS designers tried to address this by applying a more encompassing definition, which they assumed would more accurately capture the social and economic realities of South African households. However, in so doing they fell into a number of conceptual and data collection 'traps' from which the following lessons can be learnt:

I. Data collection within the extremely fluid and flexible financial and social contexts of South African 'households' requires very clear concepts and definitions for interviewers to work with.

2. Survey designers need to recognise that the way in which interviewers interpret and operationalise survey concepts can impact greatly on the quality of data collected. This is especially pertinent in multilingual, multi-cultural settings such as South Africa. The appropriate skills are also necessary for interviewers to deal effectively with organisationally and/or structurally complex 'household' settings.

3. Replacing one definition with a 'better' one does not necessarily address the complexity of 'household' contexts; all definitions make as- 
sumptions about the relationships between categories such as financial, residential, support, etc., which need to be critically examined during the design phase. Further research is also required to more fully understand the relationship between the social and financial contexts of South African 'households'.

Authors Contributions: AK, SR and EC conceived the research design; $A K, S R$ and EC conducted the household re-interviews; AK, SR and EC were involved in the interviewer interviews with AK leading the group interviews; AK drafted the article; all authors commented on and revised the final submission.

\section{References}

Africa Centre for Health and Population Studies. (2007). The Africa Centre Demographic Information System (ACDIS). [Online] Available at: http://www.africacentre.ac.za/Default.aspx?tabid $=333$

[Accessed 21 March 2013].

Bauman, Z. (1988). Legislators and Interpreters. Cambridge: Polity.

Beaman, L. and Dillon, A. (2010). Do Household Definitions Matter in Survey Design? Results from a Randomized Survey Experiment in Mali. IFPRI Discussion Paper 01009:32.

Budlender, D. (2003). 'The Debate about Household Headship.' Social Dynamics 29 (2):48-72.

Cloke, J. (2007). 'Gender, Taboo and Deceit: The Alternative Truths of Household Research.' GeoJournal 70:33-45.

De Clercq, B., Van Aardt, C.J., Van Tonder, J.A., Venter, J.M.P., Scheepers, D. and Kriel, A. (20I2). Household Wealth in South Africa, 20II. Pretoria: University of South Africa (Unisa), Bureau of Market Research.

Eurosystem Household Finance and Consumption Network. (2009). HFCS Core Variables Catalogue. Frankfurt am Main, Germany.

Fisher, M., Reimer, J.J. and Carr, E.R. (20I0). 'Who Should be Interviewed in Surveys of Household Income?' World Development 38 (7):966-973.

Guyer, J.I. (1981). 'Household and Community in African Studies.' African Studies Review 24 (2/3):87-137.

Guyer, J. and Peters, P.E. (1987). 'Conceptualizing the Household - Issues of Theory and Policy in Africa - Introduction.' Development and Change 18:197-214.
Hosegood, V., Benzler, J. and Solarsh, G. (2005). 'Population Mobility and Household Dynamics in Rural South Africa: Implications for Demographic and Health Research.' Southern African Journal of Demography 10 (I and2):43-67.

Hosegood, V. and Timaeus, I. (2006). Household Composition and Dynamics in KwaZulu Natal, South Africa: Mirroring Social Reality in Longitudinal Data Collection. In African Household: Censuses and Surveys, edited by E. van de Walle. New York: Sharpe.

Jones, S. (1993). Assaulting Childhood. Children's Experiences of Migrancy and Hostel Life in South Africa. . Johannesburg: Witwatersrand University Press.

Little, P.D., Stone, M.P., Mogues, T., Castro, A.P. and Negatu, W. (2006). 'Moving in Place: Drought and Poverty Dynamics in South Wollo, Ethiopia.' The Journal of Development Studies 42 (2): 200-225. doi: 10. 1080/00220380500405287

Mushongah, J. and I. Scoones (20I2). 'Livelihood Change in Rural Zimbabwe over 20 Years.' Journal of Development Studies 48 (9): I 24 I- 1257

Murray, C. (198I). Families Divided: The Impact of Migration in Lesotho. Cambridge: CUP.

O'Laughlin, B. (1998). 'Missing Men? The Debate over Rural Poverty and Women-headed Households in Southern Africa.' The Journal of Peasant Studies 25: I-48.

Rabe, M. (2006). Black Mineworkers' Conceptualisation of Fatherhood: A Sociological Exploration in the South African Gold Mining Industry. Pretoria: Unisa.

Rabe, M. (2008). 'Can the 'African household' be Presented Meaningfully in Large-scale Surveys?' African Sociological Review 12:167-181.

Randall, S., Coast, E. and Leone, T. (20II). 'Cultural Constructions of the Concept of Household in Sample Surveys.' Population Studies 65 (2):217229.

Rao, N.J.U. (1992). Gaps in Definitions and Analysis: A Sociological Perspective. In Finding the household: Conceptual and Methodological Issues, edited by K. Saradamoni. New Delhi: Sage.

South African Advertising Research Foundation. (20I2). All Media and Products Survey, 20I2A. Johannesburg.

Spiegel, A. (1996). 'Introduction: Domestic Fluidity in South Africa.' Social Dynamics 22:5-6.

Statistics South Africa. (2007). Community Survey 2007: Methodology, Processes and Highlights of Key Results. Pretoria. 
Statistics South Africa. (2010). General Household Survey, Selected Development Indicators. Pretoria.

System of National Accounts. (2008) The System of National Accounts 2008. New York: European Communities, International Monetary Fund, Organisation for Co-operation and Development, United Nations and World Bank.

Townsend, N.W. (1997). 'Men, Migration, and Households in Botswana: An Exploration of Connections over Time and Space.' Journal of Southern African Studies 23 (3):405-420.

United Nations Department of Economic and Social Affairs. (2008). Principles and Recommendations for Population and Housing Censuses (Revision 2). New York: United Nations.

Van Aardt, C.J. (2007). Population and Household Projections for South Africa by Province and Population Group, 200I-202I. Pretoria: University of South Africa (Unisa), Bureau of Market Research.

Whitehead, A. (2006). 'Persistent poverty in North East Ghana.' Journal of Development Studies 42 (2):278-300.

World Bank. (2004). The Marrakech Action Plan for Statistics: Better Data for Better Results. An Action Plan for Improving Development Statistics. Presented to the Second International Roundtable on Managing for Development Results, Marrakech, Morocco, 4-5 February 2004.

\section{Notes:}

i. ACDIS collects demographic and health data on all household members, resident and nonresident, from registered households within a demographic surveillance area in KwaZuluNatal, South Africa. The data is collected every 6 months (Africa Centre for Health and Population Studies, 2007).

ii. A multi-stage rim weighting methodology was applied to a multi-stage stratified random sampling process. Wards were randomly sampled from both metropolitan and nonmetropolitan municipalities within all nine provinces. Systematic random sampling was used to select households for face-to-face interviews and individuals were randomly sampled from telephone directories for telephonic interviews. A sampling frame was developed using the municipal matrix from the 2007 Community Survey results (Statistics South Africa, 2007) and adjusted with the 2011 mid-year population projection (Van
Aardt, 2007; De Clercq, Van Aardt, Van Tonder, Venter, Scheepers, and Kriel, 20I2).

iii. I) persons usually resident but temporarily absent from dwelling (for reasons of holiday, travel, work, education or similar)

2) children of the household being educated away from home

3) persons absent for long periods, but having household ties: persons working away from home

4) persons temporarily absent but having household ties: persons in hospital, nursing home, boarding school or other institution

iv. The Reconstruction and Development Programme (RDP) is an integrated, coherent socioeconomic policy framework developed by the South African Government. It seeks to mobilise all South Africa's people and the country's resources toward the final eradication of apartheid and the building of a democratic, non-racial and non-sexist future (http://www.polity.org.za/polity/govdocs/rdp/rdp I.html\# I.I). 